\title{
Poverty and Social Behavior of the Urban Community
}

\author{
Husain Hamka \\ Faculty of Social Politic, 45 University of Makassar - Indonesia \\ Tahir Kasnawi \\ Faculty of Social Politic, Makassar State University of Indonesia \\ Mahmud Tang \\ Faculty of Social Politic, Makassar State University of Indonesia \\ Darma Manda \\ Faculty of Social Politic, Makassar State University of Indonesia
}

Accepted: November 11, 2012 Published: December 27, 2012

Doi:10.5296/jsr.v3i2.2794 URL: http://dx.doi.org/10.5296/jsr.v3i2.2794

\begin{abstract}
Money is a very attractive item for any persons to be pursued. In the sociological perspective, the poverty is a function of a social system where money is within it. Many persons are using money but they do not understand the actual use of money because they see their demand of money as not bargained. Poverty is seen as a theology where people can be poor at certain time and situation.
\end{abstract}

Keywords: $\quad$ Poverty, Behavior, Community, Urban

\section{Background}

Indonesia is a nation with commitment for "poverty mainstreaming" in all development policies, either at national or local development levels. Wrihatnolo, (2007), a new history of poverty eradication is begun and more intensive than previous efforts. One indication is that a specific document is prepared as the policy base for poverty eradication. This document is prepared through stages with clear rule or policy (President Decree No. 124 of 2001, jo. President Decree No. 34 of 2002). This effort are realized by placing the appropriate perspective about the consistency between strategic planning, policy, program, goal setting and mechanism to meet, to empower and to protect right base of the poor community.

The author attempts to explore this problem because the governmental programs for the community empowerment and the poverty eradication have been carried out in the form of aid. Life pattern of the community, however, is not changed after receiving governmental aid. 


\section{$\Lambda$ Macrothink}

The research conducts a deep review about poverty and social behavior of the urban community.

\section{Research Method}

This study is reviewing the poverty and the social behavior of the urban community through some perspectives such as sociology, functionalism structure, social system and social integration, and social solidarity.

The objective of research is (1) to reveal poverty and social behavior of the urban community in the life of the urban community, (2) to explain the signification of poverty in the life of the urban community, and (3) to describe the socioeconomic condition of the urban community.

The approach is qualitative with case study method. Other informants are involved purposively to supplement the existing data. Data are collected through observation and deep interview, which are then subjected to inductive analysis (Bogdan et al, 1993). Result of research indicates that the participation of stakeholder is expected to produce a comprehensive structure from many viewpoints such that the substance of poverty eradication policy can represent the interest and real demand of the poor community. Therefore, the resultant policy is a result of deep exploration into the poor community to establish more obvious implementation at local level.

\section{Result And Discussion}

\section{1. . Poverty Profile in Indonesia}

High unemployment rate is worsening the poverty rate. The issue even becomes more complicated with the elongated impact of economic crisis. Great attention has been given by the policy maker to this issue. Anticipative measures are absolutely needed to increase the public wealth. The poverty eradication program at urban level has been implemented in 1999 as the governmental step to develop the self-supporting mindset into the community and the local government in dealing the sustainable poverty.

Poverty eradication in so far is only concerning with the increase of the income of the poor community through various economic programs, but all fail to solve the poverty. The fundamental mistake is seeing the poverty as the incapability of someone in meeting the staple demand due to lower income (economic). In other words, poverty is a situation where the life of the community remains at the loss position in meeting the staple demand.

Some empowerment programs are presented to give great promise for the poor community in the urban, but the community is recognizing these programs with apathy and pragmatic and relying only on aid without further exertion. These programs may contribute to the principle "helping the poor to help themselves". The change of mindset of the poor community has 
been becoming a fundamental issue in the poverty eradication at Makassar City (Abustam, et al., 1995).

A sense of entrepreneurship is a significant factor to be internalized into the poor community. The social structure of the community seems needing for new layer to develop insight, knowledge, capacity, and skill of entrepreneurship among them such that they can manage the existing resource based on appropriate business principles, and most important, they can manage the aid capital as the compensation of poverty eradication.

Social behavior of the poor community in the urban is various through their social interaction with the immediate community. They may feel that the formation of wealth and development policies will discriminate them and put them isolated from the development. Poverty, social gap between community groups, social backwardness, and other social issues, are the consequence of the national development. The road of development, therefore, shall be improved because in the less integrative development context, some programs to anticipate the negative impact must be set to facilitate the resolution of new social issues which are often emerging after the development begins.

Poverty phenomenon constitutes a "life style" of the urban community because they are enjoying themselves as the recipient of other's aid. The government has taken many measures to suppress the poverty rate but it fails due to some factors such as the misleading of governmental aid by some parties and too many people who are financially capable but see themselves as being poor.

The emergent impression is that the aid and the development from the government are given without reviewing the vital demand of the community. Some groups even understand the poverty as a matter of "choice" made by the God for his creature to increase their recall to Him.

Through paradigm perspective, Peter Blau expresses two basic social facts, which are the common values and the norm which often manifested in the culture or sub-culture. Main issue in the sociological investigation, based on paradigm perspective, is social facts. In general, two types of social facts are understood, which are social structure and social institution. In detail, social facts may include group, certain unity of community (societies), social system, position, role, values, family, government and others.

Peter Blau insists that common values are clearly described in the reality of Indonesian life, especially the urban community. Their poverty indicators are mostly their lump settlement that is far from cleanliness and healthy life pattern, and the difficulty of meeting the economic demand. Poverty, indeed, can also influence the culture, as said by Oscar (1995) that poverty may push people to create a poverty culture.

Some causal factors of poverty in the urban community are mentioned so far, and therefore, 
poverty eradication measures are given such as empowerment through enlightenment, non-formal education, funding, and counseling. The line of thought is described as follows:

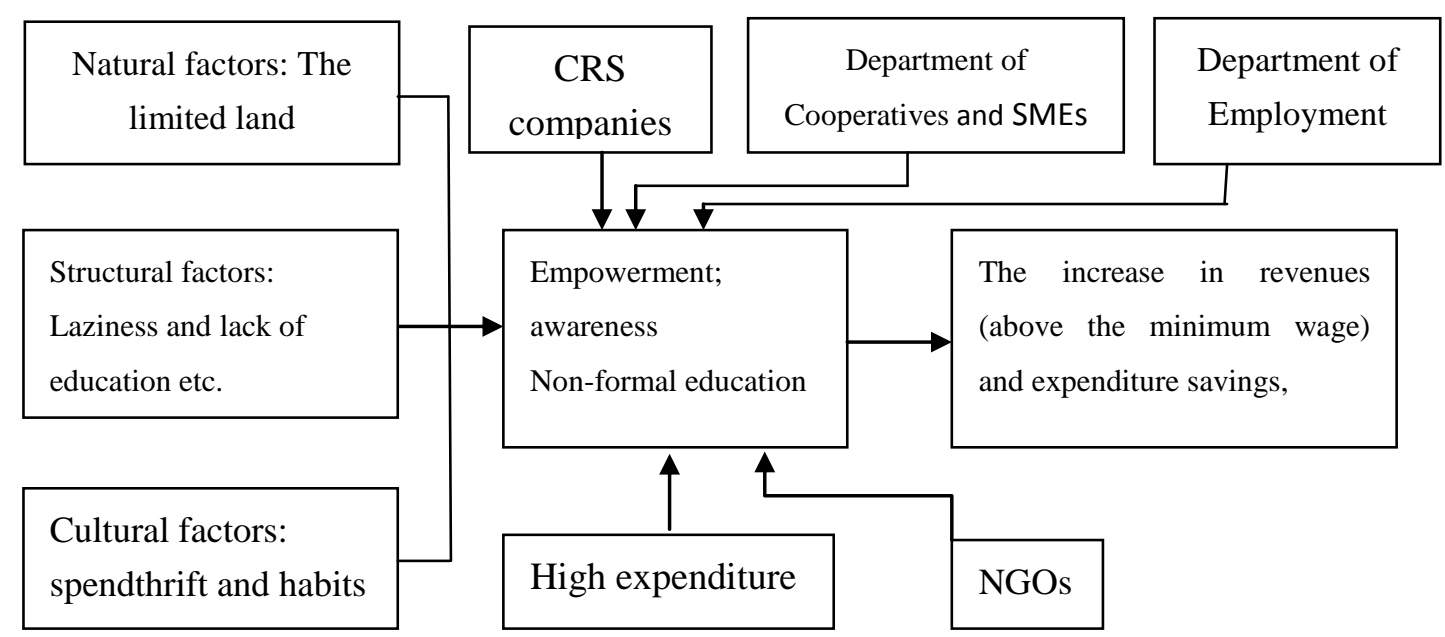

Figure 1. The Alternative Model of The Empowerment for The Urban Poor Community According to Durkheim, there are two kinds of social facts :

a. The material form. It stands for the goods which can be seen, captured and observed. The material may be a part of a real world (an external world) such as architecture and legal norm.

b. The non-material form. It is a something considered as obvious (external). Such type of social fact is emerging from human awareness, such as egoism, altruism, and opinion.

Oscar Lewis has determined that poverty occurs because people work their job by ignoring achievement. This indicator is very clear in Indonesian culture because they think that a job is to meet the demand, not to achieve something. What the achievement means here is how they maximize their effort to go out from poverty culture, such as by taking a long-term investment in the education.

The poor community, however, do not even regret of work exploitation against children. Indeed, children have been used as money machine by sending them for any freelance jobs, such as in the fish auction site where they sell plastic wrap or work as carrier laborer. It is ironic to see such social fact because it shows that the poverty motive has been shifted from structural to cultural where children are exploited by the parent to help their economic.

It is then formulated an alternative model of the urban poor community who exploit their children as the freelancer. The alternative model of poverty eradication is shown as follows. 


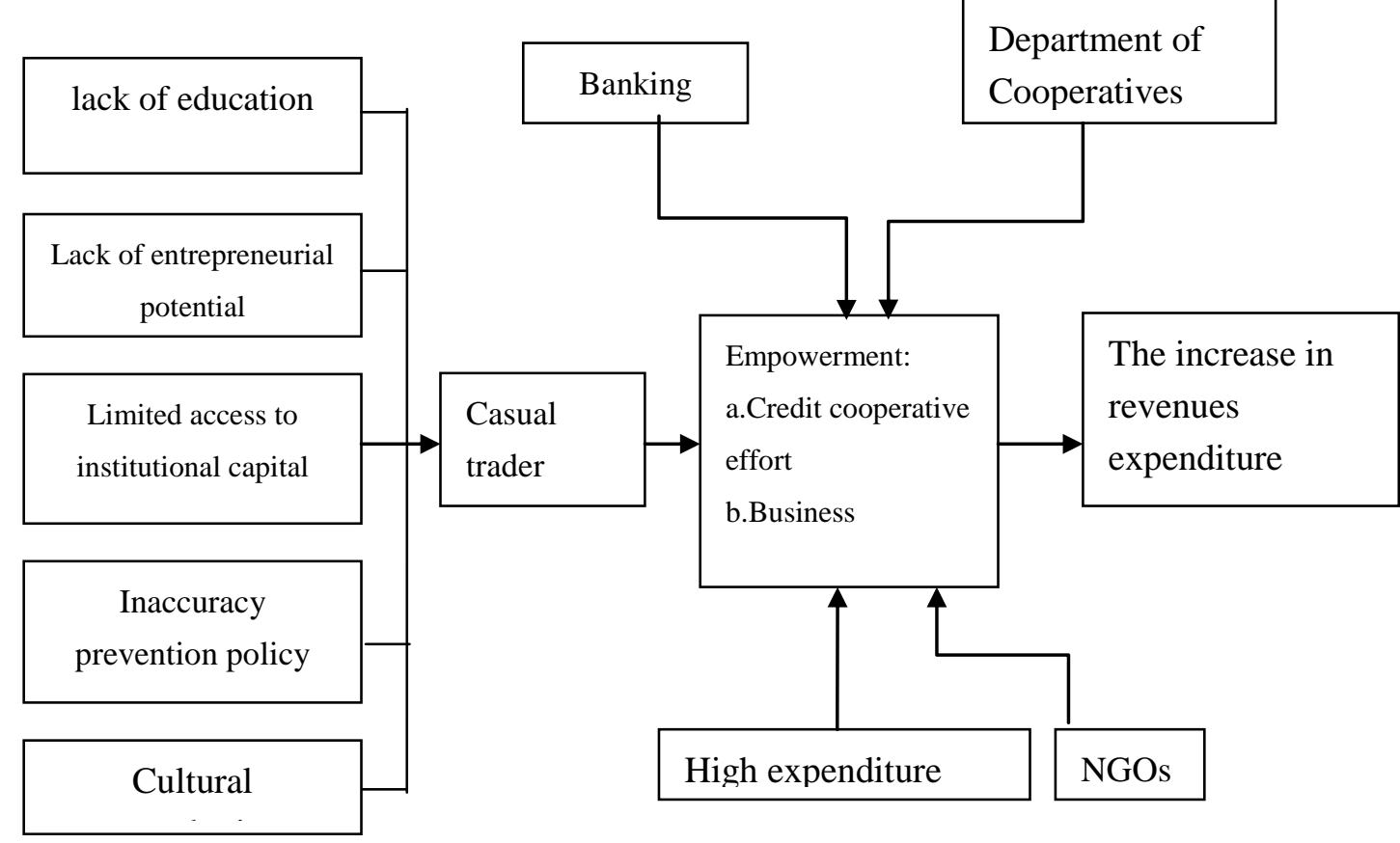

Figure 2. The Alternative Model of The Empowerment for The Urban Poor Community Exploit Their Children as The Freelancer

In the modern sociology institution, the social institution is still viewed as the relationship of norms and values which explain the activity or problem of human. Some social institutions are existed such as family, government, economic, education, religion and knowledge. The proponent of social fact paradigm gives greater emphasis on social structure or social institution. Main focus of the proponent of social fact paradigm is on the relationship between social structures and the relationship between individual and social structure.

It is admitted in the social structure that the structure may influence the developmental pattern of the community. If the structure shall use Western capitalist system, then any systems below will be exploited and suppressed such that the effort to escape from poverty must be so difficult because the movement may be structured by rule of the game. It seems that social fact paradigm explaining human behavior is still determined by social norms and social values.

Social behavior paradigm is the individual behavior during the interaction of individual with the environmental factor. This interaction will change the environment or subjected to the environmental change, and therefore, it may change the behavior. The difference between social behavior paradigm and social fact paradigm is on the control of individual behavior. Social fact paradigm concerns with macroscopic structure and the institutions affecting or controlling individual behavior, while social behavior paradigm has unclear issue to examine.

Poverty represents a fundamental issue in the development given to the people by a certain nation. The developing nation, such as Indonesia, experiences such issue. Many factors influence poverty such as income, wealth, education, access to public service (goods and 
services), location, geography, gender and environmental condition as the consideration or the influential factor.

Soekamto (1996) declares that poverty in the economic perspective is defined as the incapability of someone to meet the primary demand such that it gives bad impact on employment, morality and others. It is important to have a poverty eradication strategy through empowering the people economic because the poverty is a part of social pathology or social disease which is requiring special therapy.

The knowledge about the causal factors of poverty, therefore, is needed because poverty issue is always confused. A real strategy from the planner of poverty eradication and development management programs is necessary to facilitate the policy analysis. Garna (1992) admits that the isolated community is identified with the poverty such that they are sometimes recognized with their alienated social status. Higher population rate of the poor community will lead to lower food consumption and nutrient, lower work productivity, high mortality of infant and children, lower life expectancy, and most fundamental, lower education rate. All of these are initiating the lower wealth rate.

In other hand, Soekamto (1996) adds that the normal community has high cooperative value due to their respected social values. The urban poor community does not have sense of initiative or creativity because the individual is only depending on the help of others. Whether there is positive or negative consequence, the cooperation is a form of social interaction to establish one universal sign of the usual community.

Weber quoted in Ritzer., (2007) has said that human behavior is social behavior, and therefore, it has certain goal, which is defined clearly. It means that the behavior shall give significance (meaning) to the doer because this behavior is oriented toward other behavior of the other person.

Considering a modernity phenomenon in the economic field, Sztomka (2005) describes the modernity phenomenon as follows:

a. A very fast economic growth.

b. The primary shifting from agrarian production to the production as the core of economic sector.

c. The concentration of economic production into town and urban area.

d. The use of not-living resource to substitute the human and animal workers.

e. The distribution of technology invention throughout social life aspect.

f. The opening of free-competitive worker market with less unemployment.

g. Great concentration of worker into the factory and the giant corporation.

h. The importance of entrepreneurs, managers or "industrial captain" in controlling the production. 
The poverty is basically caused by two factors:

a. Structural. The poverty occurs due to the governmental policy in managing the economic during the scarcity, or due to the policy to increase the sale price such that it reduces the purchasing power or affordability of the people.

b. Cultural. The poverty occurs as the pattern of family life, and therefore, the poor just only gives effort to meet the demand.

Selo Soemarjan asserts two other causes of poverty. First is due to the community order constructed by the community itself in form of social classes or social strata. Second is due to organizational factor, such as the creation of rule of the game which only prevents the poor community from going out from poverty because they do not have greater role in the self-empowerment but only being suppressed and receiving the system.

Alfian (1984) proposes three mental attitudes of Indonesian which directly creates the poverty:

a. A mental attitude of farmers. The farmers live in the cultural value system which characterize them as bad, sin, and misery. Poverty among farmers is denying the future because the better future is never existed. Farmers, therefore, only wait humbly for their luck.

b. A mental attitude of nobles and employees. Such mental attitude is related to the philosophy that the bad life can be improved by working for wealth and rank. Such mental attitude is characterized by yes-person, great reliance on deep mental during the hardship, and even the use of imagination.

c. A mental attitude of person in transition. It is often found in the urban. Such person always breaks the old values. However, the new norms are not developed yet, and therefore, the breaker is easily trapped into doubt. They are recognized by their underestimation of quality, fast track for the wealthy without hard work, less responsibility, less self-confidence, and apathy. Such mental attitude is also easily subjected to the corruption, collusion and nepotism, the courage of violating the law, and the abuse of power.

Poverty profile of Indonesian is too obvious despite the hard work of Indonesian to show their personality. Alfian (1984) explore poverty by making two categories. First category is natural poverty, which means that poverty occurs due to the scarcity of resource or the lower development rate of technology. Second category is artificial poverty, which occurs due to the organizational factor where the community cannot access and use the socioeconomic structure and facility in manner of distributive and social justice.

\subsection{The Change of Community Mindset}

Abustam (1995) clarifies that the reduction of poverty rate is by changing the mindset. The 
expected mindset is that the human resource is developed through education route. Indeed, the community shall be educated and maintained to make them well growth and developed. Lower education rate and mind structure will only produce a pragmatic and permissive culture, which precedes the poverty.

The urban poor community and the urban are still remaining in the poor family category with miserable living standard. Through their resolute and perseverance, they may survive in dealing with complex socioeconomic problems. Urban development policies may improve urban sector and provide structure and infrastructure, but it will increase the anxiety of the urban about the idea of removing their life on the behalf of urban development. Poverty and backwardness of human resource are mostly "nested" in the coast region, and slump settlements are the product of the discriminative development policy.

Poverty, social gap among community groups, social backwardness, other social issues are reasonable consequences with the development of a nation. It may have great implication to the development itself. In the less integrative development context, some programs may be provided to anticipate the negative impact and to facilitate the resolution of new social issues which are often emerging after the development begins. If development is estimated as producing some social problems, some activities are planned to deal with these problems, among other the empowerment.

\subsection{The Social Behavior and A Theological Review of Poverty from Some Perspectives}

Social behavior is a mandatory condition of interdependence because living in share with others will guarantee the human (World Bank., 2003) It is already proved that human can meet their demand only with the help of the other because they are alone difficult to meet this demand. It means that life existence of human is only ascertained through supporting each other. Human, therefore, is required to have a cooperation, a respect, not disturbing other, and tolerant to the community life. Social behavior of any individuals is appeared in their response to the reciprocal relationship.

A theological review of poverty says that the poverty is a social fact. Some theologian response this statement:

\section{a. Poverty Cult View}

This group comprises to zuhud, monk, and those who admit themselves as sufi and taqassyuf (avoiding the pleasure of the secular world). They do not consider poverty as bad thing which must be avoided, or as a problem to be solved. Poverty is God's gift to his beloved creatures to keep their heart recalling the end of the day, the sin of the secular world, the importance of having relationship with the God, and the importance of empathy to other.

\section{b. Jabariyah View}




\section{MInstitute Machin $^{\text {Mnth }}$}

The group does not recognize poverty as the disaster and misery, but as "the faith from the sky" which cannot be denied and rejected. Poverty suffered by the poor and wealthy had by the rich are God's wish. The solution offered to the poor (to escape from the poverty) is only related to moral advices to keep the poor willing to accept God's qada (wish), to be patient for secular test, and to increase their qanaah to the God's gift. The qanaah is representing the wealth warehouse which cannot be broken or eliminated.

\section{c. Individual Piety Proponent View}

This view has similar emphasis with Jabariyah but with opposite direction because it sees poverty as containing disaster and evil. Poverty is a problem of life which is needed to solve. The solution is not only by giving moral advices to keep the qanaah (as Jabariyah perspective), but also by moving one step forward. It means that by giving moral advices to the rich (bourgeoisie) to sacrifice their wealth, to do virtue thing, and to give donation, to the poor. It also means that the rich is entitled to the merit of God if they agree with this moral advice. If they reject and harm the poor, they are threatened with hell punishment.

\section{d. Capitalism View}

This view determines that poverty is a problem and misery, and who shall be responsible to the poverty is the poor themselves, not the faith, destiny or anything. The community, nation and the rich (bourgeoisie) are not taking responsibility of the poverty of the other. Everyone is responsibility of their poverty. Everybody has freedom for the use of their wealthy. It is essentially capitalism. Such ism is dominant in Europe countries at recent days. It is not surprising that the poor in the capitalist countries shall be always more disregarded than the orphans. They just do not have anything to pursue or they do not have any "places" to give their grievance.

\section{e. Socialism-Marxist View}

This group insists that eradicating the poverty and enlightening the poor are difficult unless the bourgeoisie class is destroyed, their wealthy is seized, and wealth possession regardless the income source is limited. Realizing this dream needs a persuasion with other social classes to develop a sense of jealously and prejudice, and to trigger a fire of dispute among classes in the community. In the end, the majority is winner, which is called the labor or proletariat.

\subsection{Poverty and The Function of Social System in The Community}

In the sociological perspective, Emile Durkheim expresses a social fact that poverty is a theology. It means that poverty is also a social fact in the community because poverty is becoming a part of life or even a type of job. Poverty is then representing a social action, as said by Max Weber, in which the social action is an action by someone with reaction from the other. There are some reactions such as empathy and compassion, thus stimulating the giving of goods or monies to the poor.

Dave (2009) asserts that poverty may be functional for any social systems, such as economic system, social system, cultural system and political system. 
a. The Economic Function of Poverty is:

1. To provide workers for dirty work in the community;

2. To produce social funds;

3. To open new job expected by the poor;

4. To use the used goods that cannot be used again by the rich.

\section{b. The Social Function of Poverty is:}

1. To empower social norms in the community;

2. To establish altruism to the poor who needs donation;

3. To persuade the rich to feel the life of the poor without experiencing poverty;

4. To provide progression measure (rod) for other class;

5. To help other group in seeking out the stair for upward;

6. To become a reason of the emergent rich who will help the poor through donation agencies.

Through these routes, the rich and the poor will not have a social jealousy, but to have a compassion relationship which will reduce the sense of prejudice between the rich and the poor.

\section{c. The Cultural Function of Poverty is:}

1. To provide physical laborer to build up some cultural monuments;

2. To facilitate the acceptance of the poor by the social strata above them.

\section{d. The Political Function of Poverty is:}

1. To express themselves as "the anxious group" or to act as the enemy against certain political interest;

2. To give the politician an idea of campaign that is usually not far away from an idea of helping the poor.

3. To give a reason for a more centric and stable political system.

\section{Conclusion}

Poverty is not giving advantage at all. It is always dysfunctional for the people who suffer from poverty because they live in misery and suppression to meet the demand. The poor always take the heavy and dirty works such as hard laborer, housekeeper, and other work with heavy energy and sweat. They can even work at day and night just to obtain a spoon of rice. However, in the sociological perspective, poverty is a functional for the social system.

Poverty as a theology explains that people is always given adequate finance to meet their demand. If they do not feel enough, they must be failed to appreciate God's gift.

Poverty as a theology is a matter of education. The educated people, who are theoretically acknowledging the negative impact of pursuing self-interest, still make a decision without considering the consequence. A complex life of human, mainly in modernity era, has witnessed the competition of people to accumulate the secular material without considering 
the values and norms of divinity.

\section{Acknowledgement}

Thanks to Andi Sose Foundation, Rector of University of 45 Makassar, and Community Research and Empowerment Organization in the University of 45 Makassar, for their financial support to this research. Great appreciation is also given to the government and people of Makassar Municipality, the government and people of Takalar District for their willingness to provide support, facility and cooperation during the research.

\section{References}

Abustam, M. Idrus. 1995. The concept of poverty in Indonesia. Population Studies Center, Hasanuddin University.

Alfian, 1984, Structural poverty an anthology, Jakarta.

Bogdan dan Taylor. 1993. Basics of qualitative research. Surabaya: National Business.

Dave Dimmell. Kananlua, P. S (2009). Community Empowerment Model for Poverty Alleviation in Sub Air Marl, North Bengkulu, National Strategic Research Director of Higher Education, University of Bengkulu, Bengkulu.

Garna, Judistira, (1992), Theories of Social Change, London; Padjajaran University

Oscar, 1995, Culture Poverty: in Urban Poverty, edited by Parsudi Suparlan, Jakarta-Sinar Harapan-Obor.

Ritzer, George. 2007, Sociology of Science paradigm Ganda, (translated by Alimandan): Jakarta; Raja Grafindo

Soekamto,. 1996. Max Weber: Basic Concepts in Sociology. Jakarta: Rajawali.

Sztomka. Piotr. 2005, The Sociology of Social Change, dialihbahasakan oleh Alimandan dengan judul Sosiologi Perubahan Sosial, Cet. II; Jakarta; Prenada Media.

Wrihatnolo, RR \& Riant, ND (2007) Empowerment Management: An Introduction and Guide for Community Empowerment. Unpublished paper.

World Bank (2003) Poverty: Vulnerabilities, Social Gaps, and Rural Dynamics, Washington D.C. 